Check for updates

Cite this: RSC Adv., 2018, 8, 3418

\title{
Photocurable ABA triblock copolymer-based ion gels utilizing photodimerization of coumarin $\dagger$
}

\author{
Ryota Tamate, (DD a Takeshi Ueki, (DD ${ }^{\mathrm{b}}$ Aya Mizutani Akimoto, (D) ${ }^{\mathrm{c}}$ Ryo Yoshida, (D) \\ Toshiyuki Oyama, (D) ${ }^{a}$ Hisashi Kokubo (D) a and Masayoshi Watanabe (DD *a
}

Herein, we develop a photocurable ABA triblock copolymer-based ion gel, which can be converted from a thermally processable, physically crosslinked ion gel to a thermally and mechanically stable, chemically crosslinked ion gel via photoinduced dimerization. The A block consists of a random copolymer of $\mathrm{N}$ isopropylacrylamide and a coumarin-containing acrylate monomer, while the B block consists of an ionic liquid-philic poly(ethylene oxide). Due to the upper critical solution temperature-type phase behavior of the A block, the ABA triblock copolymer undergoes gel-to-sol transitions in a hydrophobic ionic liquid as the temperature is increased. Furthermore, under ultraviolet (UV) light irradiation, the physical crosslinks formed by association of the A blocks in the gel at low temperatures become chemically crosslinked as a result of photodimerization of the coumarin moieties in the A block; this results in conversion from a thermo-reversible, physically crosslinked ion gel to a thermo-irreversible, chemically crosslinked ion gel. The rheological changes of the ion gel upon UV irradiation have been investigated in detail. In addition, photopatterning of the ion gel has been realized by exploiting the photocurable behavior of the ABA triblock copolymer in the ionic liquid.

Received 9th December 2017

Accepted 9th January 2018

DOI: $10.1039 / c 7 r a 13181 j$

rsc.li/rsc-advances aggregates to form a micellar core. Above the chain overlap polymer concentration, the micellar core formed by the association of A blocks is bridged by IL-philic PEO blocks, resulting in a percolated micellar network (i.e., a gel state). At high temperatures above the UCST-type phase transition temperature, the associated A blocks become soluble in ILs. Consequently, gel-to-sol transition is observed with increasing temperature. This low-temperature gel/high-temperature sol behaviour provides easy handling, enabling liquid processing at high temperatures without the use of additional solvents; furthermore, a solid form is maintained during lowtemperature use.

One of the drawbacks of thermoresponsive gels based on ABA triblock copolymers is the mechanical integrity. As the association of A blocks is a transient physical crosslink, there is a finite relaxation time. ${ }^{15}$ Therefore, over a sufficiently long timescale, the physical crosslinks can relax and creep flow can occur. ${ }^{\mathbf{1 6 , 1 7}}$ In addition, when the sol-gel transition temperature is near the operating temperature range, the mechanical properties of the gel are susceptible to subtle temperature fluctuations. On the other hand, a higher sol-gel transition temperature necessitates a high processing temperature that is unsafe and entails high energy consumption.

To improve the mechanical stability of physically crosslinked gels, post-chemical crosslinking of physically crosslinked gels have been developed for both hydrogel ${ }^{18-21}$ and ion-gel systems. ${ }^{22,23}$ Seminal work by Lodge et al. demonstrated the chemical crosslinking of ABA triblock copolymer-based ion gels
${ }^{a}$ Department of Chemistry and Biotechnology, Yokohama National University, 79-5 Tokiwadai, Hodogaya-ku, Yokohama 240-8501, Japan. E-mail: mwatanab@ynu.ac.jp ${ }^{b}$ National Institute for Materials Science (NIMS), 1-1 Namiki, Tsukuba, Ibaraki, 305o044, Japan

${ }^{c}$ Department of Materials Engineering School of Engineering, The University of Tokyo, 7-3-1 Hongo, Bunkyo-ku, Tokyo, 113-8656, Japan

$\dagger$ Electronic supplementary information (ESI) available. See DOI: 10.1039/c7ra13181j 


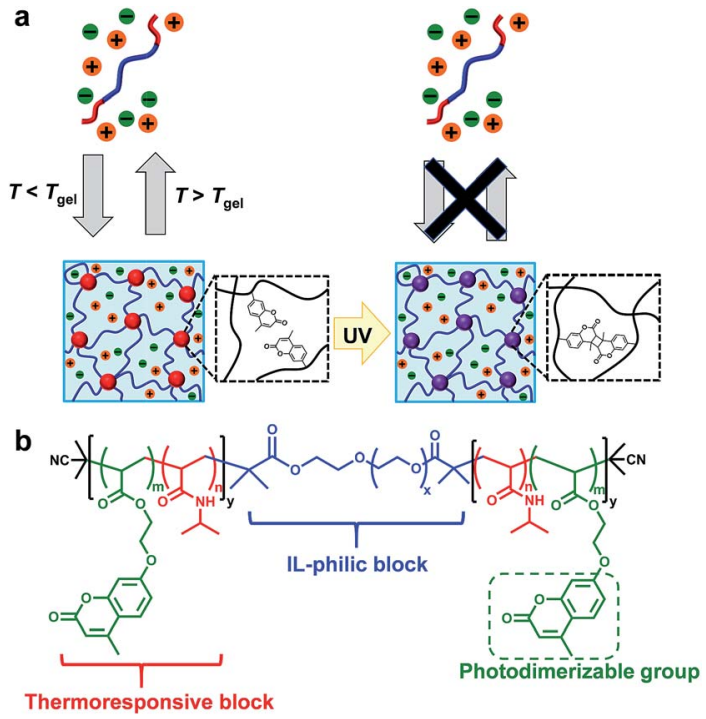

Fig. 1 (a) Schematic illustration of an ABA triblock copolymer-based photocurable ion gel. (b) Chemical structure of the ABA triblock copolymer.

by the introduction of azide-functionalized styrene units into the IL-phobic A block. ${ }^{22,23}$ We have also previously reported thermo/photoresponsive ABA triblock copolymer-based hydrogels whose viscoelasticity could be dynamically modulated by photodimerization of coumarin moieties introduced into the A block, resulting in a significant effect on the proliferation behaviour of encapsulated cells. ${ }^{21}$ Herein, our previously developed photo/thermoresponsive ABA triblock copolymer has been extended to an IL system for the first time. We demonstrate ABA triblock copolymer-based photocurable ion gels in which temperature-dependent sol-gel transitions attributed to the UCST nature of the A block in ILs were observed before UV irradiation. After UV light irradiation, we obtained photodimerization-induced chemically crosslinked ion gels that maintained their gel state irrespective of temperature (Fig. 1a).

\section{Results and discussion}

The ABA triblock copolymer used in this study was composed of a photo/thermoresponsive A block and an IL-philic B block. The A block is a random copolymer of $N$-isopropylacrylamide (NIPAm) and 7-(2-acryloyloxyethoxy)-4-methylcoumarin (coumarin acrylate; CA), and the B block is IL-philic PEO (Fig. 1b). The coumarin units, which are known to undergo [2+ 2] photocycloaddition when exposed to UV light, ${ }^{24,25}$ were introduced into the A block to chemically crosslink the micellar core. The ABA triblock copolymer, P(NIPAm- $r$-CA)- $b$-PEO- $b$ $\mathrm{P}$ (NIPAm- $r$-CA), was successfully synthesized by reversible addition-fragmentation chain transfer (RAFT) polymerization of NIPAm and CA with PEO macro chain transfer agent (PEO-CTA) (Scheme S1, Fig. S1 and S2 $\dagger$ ). The results of polymer characterization are summarized in Table 1 . The molar ratio of NIPAm and $\mathrm{CA}$ was set at $94.5: 5.5$. In this study, the ABA triblock
Table 1 Characterization results for PEO-CTA and the ABA triblock copolymer

\begin{tabular}{llll}
\hline & $M_{\mathrm{n}}{ }^{a}(\mathrm{kDa})$ & $\mathrm{PDI}^{b}$ & {$[\mathrm{CA}] /[\mathrm{NIPAm}]^{c}(\mathrm{~mol} \%)$} \\
\hline PEO-CTA & 35.0 & 1.08 & \\
ABA & $17.5-35.0-17.5$ & 1.36 & $5.5 / 94.5$
\end{tabular}

${ }^{a}$ Number-averaged molecular weight calculated from ${ }^{1} \mathrm{H}$ nuclear magnetic resonance (NMR). ${ }^{b}$ Polydispersity index (PDI) measured using gel permeation chromatography (GPC). ${ }^{c}$ Molar ratio of CA over NIPAm measured using ${ }^{1} \mathrm{H}$ NMR.

copolymer was dissolved in a hydrophobic IL, 1-butyl-3methylimidazolium hexafluorophosphate $\left(\left[\mathrm{C}_{4} \mathrm{mim}\right] \mathrm{PF}_{6}\right)$, in which PNIPAm is known to undergo UCST phase transition. ${ }^{26}$

The photosensitivity of a dilute solution of the ABA triblock copolymer in $\left[\mathrm{C}_{4} \mathrm{mim}\right] \mathrm{PF}_{6}$ was investigated by UV-vis spectroscopy. Fig. 2a shows the time-dependent UV-vis spectra of a solution of $0.1 \mathrm{wt} \%$ ABA triblock copolymer in $\left[\mathrm{C}_{4} \mathrm{mim}\right] \mathrm{PF}_{6}$ under UV irradiation $\left(\lambda=365 \mathrm{~nm}, 20 \mathrm{~mW} \mathrm{~cm}^{-2}\right)$. The characteristic absorbance peak at $320 \mathrm{~nm}$ is ascribed to undimerized coumarin moieties introduced into the ABA triblock copolymer. The absorbance peak decreases under UV irradiation; this indicates that the photodimerization reaction of the coumarin moieties proceeds in $\left[\mathrm{C}_{4} \mathrm{mim}\right] \mathrm{PF}_{6}$. The dimerization degree of the coumarin units can be calculated from the decrease in the intensity of the absorbance peak (Fig. 2a, inset). The reaction rate of photodimerization in $\left[\mathrm{C}_{4} \mathrm{mim}\right] \mathrm{PF}_{6}$ is relatively slow compared to that in water..$^{21,27,28}$ This could be explained by the high viscosity of the ILs, which retards the intermolecular collision probability. However, taking into account the fact that a number of coumarin units are incorporated into one A block (8 molecules on average, from ${ }^{1} \mathrm{H}$ NMR data), the majority of $\mathrm{A}$ blocks are considered to be crosslinked even at a low degree of dimerization.

The temperature dependence of the hydrodynamic radius $\left(R_{\mathrm{h}}\right)$ of $1 \mathrm{wt} \% \mathrm{ABA}$ triblock copolymer in $\left[\mathrm{C}_{4} \mathrm{mim}\right] \mathrm{PF}_{6}$ before and after UV irradiation was investigated by dynamic light scattering (DLS) measurements (Fig. 2b). Before UV light irradiation, the $R_{\mathrm{h}}$ value decreases from around $20 \mathrm{~nm}\left(<35^{\circ} \mathrm{C}\right)$ to below $10 \mathrm{~nm}$ $\left(>50{ }^{\circ} \mathrm{C}\right)$ with increasing temperature; this could be attributed to
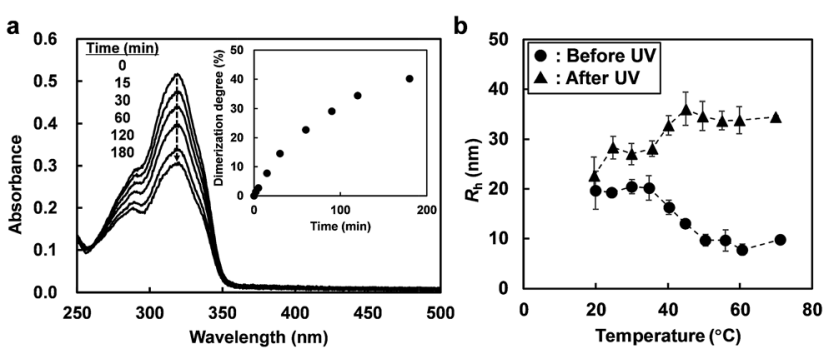

Fig. 2 (a) Change in the UV-vis spectra of a solution of 0.1 wt\% ABA triblock copolymer in $\left[\mathrm{C}_{4} \mathrm{mim}_{\mathrm{P}} \mathrm{PF}_{6}\right.$ under UV light $(\lambda=365 \mathrm{~nm}, 20 \mathrm{~mW}$ $\mathrm{cm}^{-2}$ ). (Inset) change in the degree of dimerization observed under UV light. (b) Temperature dependence of $R_{\mathrm{h}}$ values for the $1 \mathrm{wt} \% \mathrm{ABA}$ triblock copolymer in $\left[\mathrm{C}_{4}\right.$ mim] $\mathrm{PF}_{6}$ before and after UV irradiation for $2 \mathrm{~h}$. 
upper critical micellization temperature (UCMT) behaviour of the ABA triblock copolymer. On the other hand, after UV light irradiation at $30{ }^{\circ} \mathrm{C}$, the $R_{\mathrm{h}}$ value increases at higher temperatures. Under UV irradiation, the coumarin moieties present in the micelle cores form $[2+2]$ cyclobutane rings that act as chemical crosslinking points. Therefore, the permanent chemical crosslinks inhibit the micelle-to-unimer transition that occurs upon heating. Instead, at high temperature, the crosslinked A blocks became IL-philic and an increase in $R_{\mathrm{h}}$ is induced as the micelle core is swollen by $\left[\mathrm{C}_{4} \mathrm{mim}\right] \mathrm{PF}_{6}$. It should be noted that after UV light irradiation, a slight increase in $R_{\mathrm{h}}$ values, even at low temperatures below the UCMT, and a broader distribution of $R_{\mathrm{h}}$ values (reduced second cumulant values of $\mu_{2} / \Gamma^{2}=0.32$ and 1.31 at $30{ }^{\circ} \mathrm{C}$ before and after UV irradiation, respectively) were observed, suggesting that not only intramicellar but also intermicellar chemical crosslinking has occurred. Actually, a small quantity of large aggregates attributed to the intermicellar bridging in addition to small spherical micelles was confirmed by cryogenic transmission electron microscopy for ABA triblock copolymers showing UCMT behaviour in ILs. ${ }^{29}$

With increasing polymer concentration, micelle cores formed by association of P(NIPAm- $r$-CA) blocks were bridged by IL-philic PEO blocks, leading to a percolating micellar network. Disordered micellar structures for ABA triblock copolymerbased ion gels were previously observed by atomic force microscope measurements. ${ }^{10}$ From qualitative inversion tests, we found that ion gels were formed at room temperature at a polymer concentration as low as $3 \mathrm{wt} \%$ (Fig. S3†). Fig. 3a shows the variation of the storage $\left(G^{\prime}\right)$ and loss $\left(G^{\prime \prime}\right)$ moduli of a $5 \mathrm{wt} \%$ ABA triblock copolymer dissolved in $\left[\mathrm{C}_{4} \mathrm{mim}\right] \mathrm{PF}_{6}$ upon temperature changes without UV irradiation. At low temperature, $G^{\prime}$ is higher than $G^{\prime \prime}$, indicating the gel state. When the temperature is increased, both $G^{\prime}$ and $G^{\prime \prime}$ decrease; finally, $G^{\prime \prime}$ becomes higher than $G^{\prime}$ (i.e., the sol state). This could be explained by the fact that percolated micellar networks are dissociated to unimers due to the UCST-type phase behaviour of the P(NIPAm-r-CA) block. The gel-to-sol transition temperature $\left(T_{\text {gel }}\right)$, defined as the crossover of $G^{\prime}$ and $G^{\prime \prime}$, was determined to be $50.1{ }^{\circ} \mathrm{C}$. Consistent with the temperature sweep measurements, frequency sweep measurements (Fig. $3 \mathrm{~b}$ ) indicate that the polymer solution is in the gel state at $30^{\circ} \mathrm{C}$, with a $G^{\prime}$ larger than $G^{\prime \prime}$ over the entire frequency range $\left(\omega=0.1-100 \mathrm{rad} \mathrm{s}^{-1}\right)$; in contrast, terminal flow behaviour $\left(G^{\prime} \propto \omega^{2}\right.$ and $\left.G^{\prime \prime} \propto \omega\right)$ indicative of a liquid state was observed at $80^{\circ} \mathrm{C}$. At an intermediate temperature $\left(55^{\circ} \mathrm{C}\right)$ near the $T_{\text {gel }}$ determined by the temperature sweep measurement, both $G^{\prime}$ and $G^{\prime \prime}$ show similar powerlaw behaviour $\left(G^{\prime} \sim G^{\prime \prime} \propto \omega^{0.5}\right)$. Strain resistance of the ion gel at $30^{\circ} \mathrm{C}$ was also investigated, as shown in Fig. 3c. The ion gels show linear rheological responses (i.e., $G^{\prime}$ and $G^{\prime \prime}$ are not strain dependent) within the strain range of 0.1 to $200 \%$; even at $1000 \%$ strain, breakdown of the gel network was not observed.

The effect of UV light irradiation on the rheological properties of an ion gel composed of $5 \mathrm{wt} \%$ ABA triblock copolymer in $\left[\mathrm{C}_{4} \mathrm{mim}\right] \mathrm{PF}_{6}$ was investigated. During UV light irradiation at $30{ }^{\circ} \mathrm{C}$, a continuous increase in $G^{\prime}$ and decrease in $G^{\prime \prime}$ were observed (Fig. S4 $\dagger$ ). Incidentally, the loss tangent $\left(\tan \delta=G^{\prime \prime} / G^{\prime}\right)$ decreased upon UV irradiation. This clearly suggests that the stiffening of the ion gel was induced by photodimerization of the coumarin moieties in the micelle cores. Time variation of UV-vis spectra for the ion gel under UV irradiation was also investigated (Fig. S5 $\dagger$ ). The dimerization degree of coumarin moieties in the ion gel reached $40 \%$ after $2 \mathrm{~h}$, which was slightly higher than that in the diluted polymer solution shown in Fig. 2a. This could be explained by the increased collision probability of coumarin moieties in the concentrated system. The temperature dependence of $G^{\prime}$ and $G^{\prime \prime}$ for the ABA triblock copolymer solution in $\left[\mathrm{C}_{4} \mathrm{mim}\right] \mathrm{PF}_{6}$ before and after UV irradiation is shown in Fig. 4a. After UV irradiation, the gel-to-sol transition upon heating is no longer observed, and a gel-like consistency was maintained over the temperature range of 20$70{ }^{\circ} \mathrm{C}$. Slight decreases in the values of $G^{\prime}$ and $G^{\prime \prime}$ were observed around $T_{\text {gel }}$, which implies softening of the crosslinked micelle core due to swelling with $\left[\mathrm{C}_{4} \mathrm{mim}\right] \mathrm{PF}_{6}$. Frequency sweep and stress relaxation measurements were conducted at $30{ }^{\circ} \mathrm{C}$ to investigate the differences between the rheological behaviour before and after UV irradiation in detail (Fig. $4 \mathrm{~b}$ and c). From the frequency sweep measurements (Fig. 4b), we found that the difference in $G^{\prime}$ is more pronounced in the low frequency region. In addition, the stress relaxation tests (Fig. 4c) reveal that the long-term rheological behaviour has been significantly modulated by UV light irradiation. Before UV light irradiation, significant stress relaxation is observed, and half of the initial stress is relaxed after about $300 \mathrm{~s}$. On the other hand, after UV light irradiation, the ion gel retains $80 \%$ of the initial stress, even after $1000 \mathrm{~s}$. The marked difference in the stress relaxation
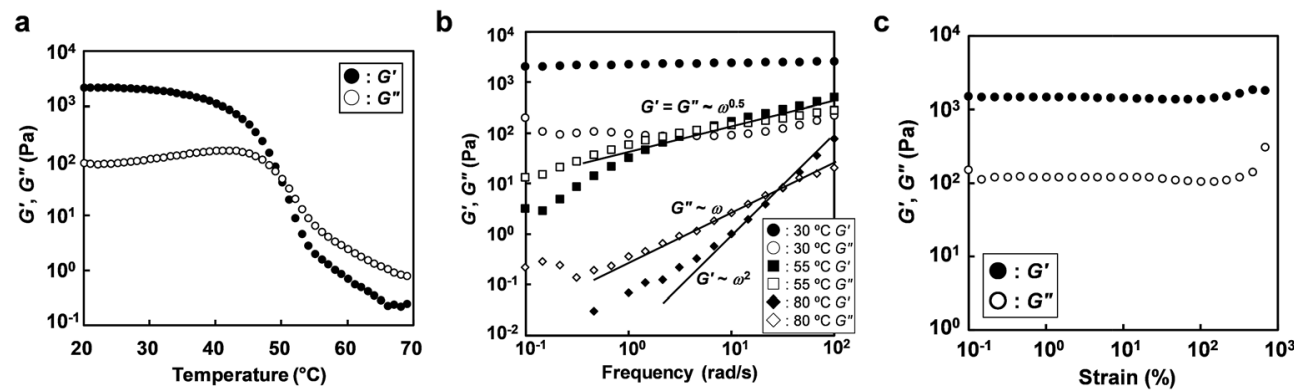

Fig. 3 (a) Temperature dependence $\left(1 \mathrm{rad} \mathrm{s}^{-1}\right)$, (b) frequency dependence at different temperatures and (c) strain dependence (1 rad $\mathrm{s}^{-1}$ ) of storage $\left(G^{\prime}\right)$ and loss $\left(G^{\prime \prime}\right)$ moduli for a solution of $5 \mathrm{wt} \%$ ABA triblock copolymer in $\left[\mathrm{C}_{4} \mathrm{mim}_{\mathrm{PF}}\right.$. 

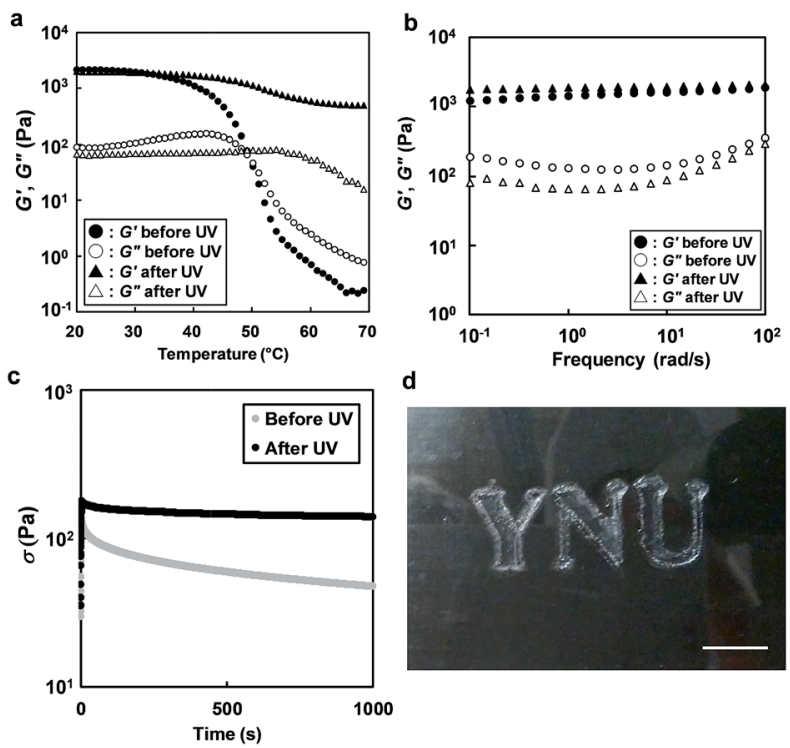

Fig. 4 (a) Temperature dependence of $G^{\prime}$ and $G^{\prime \prime}$ for the 5 wt\% ABA triblock copolymer in [ $\mathrm{C}_{4} \mathrm{mim}_{\mathrm{PF}} \mathrm{P}_{6}$ before and after UV irradiation $(\lambda=$ $365 \mathrm{~nm}, 20 \mathrm{~mW} \mathrm{~cm}^{-2}, 2 \mathrm{~h}$ ) at a frequency of $1 \mathrm{rad} \mathrm{s}^{-1}$ and a strain of $1 \%$. (b and c) Frequency dependence of $G^{\prime}$ and $G^{\prime \prime}(b)$ and stress relaxation measurements (c) at $30{ }^{\circ} \mathrm{C}$ for the ion gel (5 wt\% ABA triblock copolymer in $\left[\mathrm{C}_{4}\right.$ mim] $\mathrm{PF}_{6}$ ) before and after UV irradiation. (d) Photograph of the patterned ion gel at room temperature. Scale bar: $1 \mathrm{~cm}$.

behaviour could be attributable to the different types of crosslinks. ${ }^{30}$ Before UV irradiation, the crosslinks of the ion gel are formed by physical association of the A blocks; these crosslinks have a finite relaxation time. After UV irradiation, photodimerization of the coumarin moieties occurs within the association of the A blocks, converting the reversible physical crosslinks to permanent chemical crosslinks that have an infinite relaxation time. In contrast to the significant rheological changes, the ionic conductivity before and after UV irradiation is almost unchanged, suggesting that the photodimerization reaction in the associated A block did not affect the ionic mobility (Fig. S6 $\dagger$ ).

Finally, photopatterning of the ion gel was demonstrated by exploiting the photo-curing feature of the ion gel. The $5 \mathrm{wt} \%$ ABA triblock copolymer in $\left[\mathrm{C}_{4} \mathrm{mim}\right] \mathrm{PF}_{6}$ was cast onto a glass slide, forming an ion-gel film at room temperature. Then, the ion gel was irradiated with UV light through a photomask. The UV-irradiated ion gel was rinsed in chloroform, and the nonirradiated area (i.e., the physically crosslinked ion gel) was removed to obtain a patterned ion gel (Fig. 4d). As expected, the patterned ion gel maintained its shape integrity, even at temperatures above $T_{\text {gel }}$.

\section{Conclusions}

In conclusion, we fabricated a photocurable ion gel based on an ABA triblock copolymer. Before UV light irradiation, the ABA triblock copolymer in the hydrophobic IL showed reversible solgel transitions in response to temperature changes, due to the UCST-type solubility change of the A blocks. In contrast, after
UV light irradiation, the ion gels maintained their solid-like integrity, irrespective of temperature; this could be attributed to photodimerization-induced chemical crosslinking of the micelle cores. The thermoreversible nature of the ion gel and the photoresponsive conversion from a temperature-responsive physical ion gel to a temperature-independent chemical ion gel enable facile processing at temperatures above $T_{\text {gel }}$ and ensure the post-processing mechanical stability of the ion gel.

\section{Conflicts of interest}

There are no conflicts to declare.

\section{Acknowledgements}

This work was financially supported by Grants-in-Aid for Scientific Research (\#S-15H05758) and Specially Promoted Research on Iontronics funded by MEXT, Japan. R. T. acknowledges Research Fellowships awarded by the Japan Society for the Promotion of Science for Young Scientists (17J00756).

\section{Notes and references}

1 M. A. B. H. Susan, T. Kaneko, A. Noda and M. Watanabe, J. Am. Chem. Soc., 2005, 127, 4976-4983.

2 T. Ueki and M. Watanabe, Macromolecules, 2008, 41, 37393749.

3 J. Le Bideau, L. Viau and A. Vioux, Chem. Soc. Rev., 2011, 40, 907-925.

4 J. H. Cho, J. Lee, Y. Xia, B. Kim, Y. He, M. J. Renn, T. P. Lodge and C. D. Frisbie, Nat. Mater., 2008, 7, 900-906.

5 K. H. Lee, M. S. Kang, S. Zhang, Y. Gu, T. P. Lodge and C. D. Frisbie, Adv. Mater., 2012, 24, 4457-4462.

6 S. Z. Bisri, S. Shimizu, M. Nakano and Y. Iwasa, Adv. Mater., 2017, 29, 1607054.

7 Y. Kitazawa, K. Iwata, S. Imaizumi, H. Ahn, S. Y. Kim, K. Ueno, M. J. Park and M. Watanabe, Macromolecules, 2014, 47, 6009-6016.

8 I. Osada, H. de Vries, B. Scrosati and S. Passerini, Angew. Chem., Int. Ed., 2016, 55, 500-513.

9 D. Zhou, G. M. Spinks, G. G. Wallace, C. Tiyapiboonchaiya, D. R. MacFarlane, M. Forsyth and J. Sun, Electrochim. Acta, 2003, 48, 2355-2359.

10 S. Imaizumi, H. Kokubo and M. Watanabe, Macromolecules, 2012, 45, 401-409.

11 C. Keplinger, J.-Y. Sun, C. C. Foo, P. Rothemund, G. M. Whitesides and Z. Suo, Science, 2013, 341, 984-987.

$12 \mathrm{~S}$. Ishii, H. Kokubo, K. Hashimoto, S. Imaizumi and M. Watanabe, Macromolecules, 2017, 50, 2906-2915.

13 Y. He and T. P. Lodge, Chem. Commun., 2007, 2732-2734.

14 T. Ueki and M. Watanabe, Chem. Lett., 2006, 35, 964-965.

15 M. E. Seitz, W. R. Burghardt, K. T. Faber and K. R. Shull, Macromolecules, 2007, 40, 1218-1226.

16 F. Tanaka and S. F. Edwards, J. Non-Newtonian Fluid Mech., 1992, 43, 247-271. 
17 H. H. Bearat, B. H. Lee and B. L. Vernon, Acta Biomater., 2012, 8, 3629-3642.

18 F. Cellesi, N. Tirelli and J. A. Hubbell, Macromol. Chem. Phys., 2002, 203, 1466-1472.

19 N. Sanabria-DeLong, A. J. Crosby and G. N. Tew, Biomacromolecules, 2008, 9, 2784-2791.

20 V. Kadam, T. Nicolai, E. Nicol and L. Benyahia, Macromolecules, 2011, 44, 8225-8232.

21 R. Tamate, T. Ueki, Y. Kitazawa, M. Kuzunuki, M. Watanabe, A. M. Akimoto and R. Yoshida, Chem. Mater., 2016, 28, 64016408.

22 Y. Gu, S. Zhang, L. Martinetti, K. H. Lee, L. D. McIntosh, C. D. Frisbie and T. P. Lodge, J. Am. Chem. Soc., 2013, 135, 9652-9655.

23 J.-H. Choi, Y. Gu, K. Hong, W. Xie, C. D. Frisbie and T. P. Lodge, ACS Appl. Mater. Interfaces, 2014, 6, 1927519281.
24 S. R. Trenor, A. R. Shultz, B. J. Love and T. E. Long, Chem. Rev., 2004, 104, 3059-3078.

25 G. Kaur, P. Johnston and K. Saito, Polym. Chem., 2014, 5, 2171-2186.

26 Z. Bai, Y. He, N. P. Young and T. P. Lodge, Macromolecules, 2008, 41, 6615-6617.

27 J. Jiang, B. Qi, M. Lepage and Y. Zhao, Macromolecules, 2007, 40, 790-792.

28 J. He, X. Tong and Y. Zhao, Macromolecules, 2009, 42, 48454852.

29 T. Ueki, Y. Nakamura, R. Usui, Y. Kitazawa, S. So, T. P. Lodge and M. Watanabe, Angew. Chem., Int. Ed., 2015, 54, 30183022.

30 X. Zhao, N. Huebsch, D. J. Mooney and Z. Suo, J. Appl. Phys., 2010, 107, 63509. 